\title{
Surgical management of recurrent disc herniations with microdiscectomy and long-term results on life quality: Detailed analysis of 70 cases
}

\author{
Serdal Albayrak, Sait Ozturk1, Emre Durdag, Ömer Ayden \\ Department of Neurosurgery, Training and Research Hospital, ${ }^{1}$ Department of Neurosurgery, School of Medicine, Firat University, Elazig, \\ Turkey
}

\begin{abstract}
Background: Aim of this paper is to recall the surgical technique used in the recurrent lumbar disc herniations (LDHs) and to share our experiences. Materials and Methods: Out of series of 1115 patients who underwent operations for LDH between 2006 and 2013, 70 patients underwent re-operations, which were included in this study. During surgery, lateral decompression performed over the medial facet joint to the superior facet joint border was seen after widening the laminectomy defect, and microdiscectomy was performed. The demographic findings of the patients, their complaints in admission to hospital, the level of operation, the condition of dural injury, the first admission in the prospective analysis, and their quality of life were evaluated through the Oswestry scoring during their postoperative $1^{\text {st }}, 3^{\text {rd }}, 6^{\text {th }}$-month and $1^{\text {st }}, 3^{\text {rd }}, 5^{\text {th }}$ and $7^{\text {th }}$-year follow-up. In the statical analysis, Friedman test was performed for the comparison of the Oswestry scores and Siegel Castellan test was used for the paired nonparametrical data. A $P<0.05$ was considered statistically significant. Results: Considering the Oswestry Index during the follow-ups, the values in the postoperative early period and follow-ups were seen to be significantly lower than those at the time of admission to hospital $(P<0.05)$. None of the patients, who re-operated by microdiscectomy, presented with iatrogenic instability in 7 years follow-up period. Conclusion: Microdiscectomy performed through a proper technique in the re-operation of recurrent disc herniations eases complaints and improves the quality of life. Long-term follow-ups are required for more accurate results.
\end{abstract}

Key words: Disc herniation, life quality, microdiscectomy, oswestry index, recurrence

\section{Introduction}

Lumbar disc herniation ( $\mathrm{LDH}$ ) is defined by the neurological findings and symptoms which occur due to the degeneration of the intervertebral discs. The prevalence of the disease is roughly between 3\% and $4 \%$; however, it was reported that $40 \%$ of all the people had experienced a dysfunction due to LDH in a period of their lives. ${ }^{[1]}$ Therefore, this disease is regarded as a major health problem. Even though it requires a few

\section{Address for correspondence:}

Dr. Sait Ozturk, Department of Neurosurgery,

School of Medicine, Firat University, Elazig 23119, Turkey.

E-mail: drsaitozturk@yahoo.com

\begin{tabular}{|l|l|}
\hline \multicolumn{2}{|c|}{ Access this article online } \\
\hline Quick Response Code: & Website: \\
\hline & www.ruralneuropractice.com \\
\hline & \\
\hline
\end{tabular}

operations, the most common field of application in the lumbar spinal surgery is the LDH. ${ }^{[2]}$ There are 3 basic techniques in the LDH surgery, which have been defined as an open discectomy, microdiscectomy, and endoscopic discectomy. Although a serious variation is seen among the proportions, $3-24 \%$ of all the patients operated on independently of the technique may need to be operated on once again. ${ }^{[3-5]}$ The most common reason for a lumbar operation in the wake of lumbar disc surgery is the lumbar re-herniation. The re-herniation defines the herniation level that is operated on, which is referred to as the herniation. ${ }^{[1]}$ The importance of the surgical technique performed is understood better once the most common reason for

This is an open access article distributed under the terms of the Creative Commons Attribution-NonCommercial-ShareAlike 3.0 License, which allows others to remix, tweak, and build upon the work non-commercially, as long as the author is credited and the new creations are licensed under the identical terms.

For reprints contact: reprints@medknow.com

How to cite this article: Albayrak S, Ozturk S, Durdag E, Ayden Ö. Surgical management of recurrent disc herniations with microdiscectomy and long-term results on life quality: Detailed analysis of 70 cases. J Neurosci Rural Pract 2016;7:87-90. 
an early operation is considered to be the herniations. Lumbar microdiscectomy in the lumbar disc surgery is a surgical technique with a low ratio of side-effect, which has been approved and commonly performed all around the world. With the advancement of the microsurgical techniques, the need for a re-operation has declined below $10 \%{ }^{[1]}$

In this study, we have aimed to describe the standard procedure we perform in the re-operation of discs by microdiscectomy and evaluate the clinical results of the patients who underwent a revision disc surgery.

\section{Materials and Methods}

Between November 2006 and May 2013, 86 patients diagnosed with the recurrent $\mathrm{LDH}$, who were selected from among 1115 patients (604 male and 511 female, age between 17 and 82, median age 44.48 years) with LDH operated on by the same surgeons, were examined prospectively for the study. 810 patients underwent surgery by epidural anesthesia and 305 patients operated under general anesthesia. Microdiscectomy performed for 1003 patients and open disc surgery performed for 112 patients. Within the first postoperative 6 months, 16 patients re-operated because of recurrence were excluded from the study, since they were considered as failed low-back surgery syndrome. 70 patients with the recurrent disc hernia who were operated on after more than 6 months were analyzed. The demographic characteristics/features of the patients, their complaints at first admission to hospital, the level of operation, the condition of dural injury, the first application in the prospective analysis, and their quality of life were evaluated through the Oswestry scoring during their postoperative $1^{\text {st }}, 3^{\text {rd }}, 6^{\text {th }}$-month and $1^{\text {st }}, 3^{\text {rd }}, 5^{\text {th }}$ and $7^{\text {th }}$-year follow-ups. All of the patients were followed for 7 years. The Oswestry scale was used in the patients' follow-up, and the control statistics were performed on this scale. In the statical analysis, Friedman test was performed for the comparison of the Oswestry scores, and Siegel Castellan test was used for the paired nonparametrical data. A $P<0.05$ was considered statistically significant.

\section{Results}

There are 70 re-operated patients observed. 46 patients $(65 \%)$ were male, and 24 patients $(35 \%)$ were female. The mean age was 44.5 (min: 30, max: 69). The follow-up period of the patients lasted between 1-month and 7 years. Two basic complaints were determined as the complaints during admission to hospital. While 58 patients (83\%) admitted to the hospital with a radicular pain, 12 patients $(17 \%)$ had mainly complaints of leg weakness. While during the physical examination, there was mostly the straight leg raise test/Laseque test positivity ( $n: 64,91 \%)$, it was determined that there was weakness at various degrees in the foot movements of 8 patients $(11 \%)$, and a foot drop in 4 patients (5\%). The recurrence time was ascertained to be 40 months ( 6 months- 19 years). While $64(91 \%)$ of the patients were opened due to the first recurrence, 6 of them (9\%) were operated on due to the second recurrence. 22 out of all the patients were the cases operated on previously by the authors of this article. Considering the levels of operation, 43 patients were operated on the $\mathrm{L}_{4-5}$ level, 18 of them on the $\mathrm{L}_{5}$ level, and 5 of them were operated on the $\mathrm{L}_{3-4}$ level. It was seen that the operation in 4 patients was performed along two distances $\left(\mathrm{L}_{4-5}, \mathrm{~L}_{5}-\mathrm{S}_{1}\right)$ [Table 1]. 58 patients underwent surgery under epidural anesthesia, whereas 12 patients operated under general anesthesia. A dural tear developed only in 4 patients (5\%). A day later, the patients with a dural tear and the others were mobilized on the same day. No other complication was observed.

Considering the Oswestry scores of the patients during the follow-ups, a significant level of decline observed $(P<0.001)$ [Table 2].

\section{Surgical technique for re-operation}

Under general anesthesia, the paravertebral muscle fascia was opened in prone position by using an old skin incision. The sharp and obtuse dissection was performed by reaching down to the former laminectomy defect by using cautery. The laminectomy defect was enlarged along up to the top of the granulation area, and a limited medial facetectomy was done until the medial edge of the superior facet joint could be visible. In this way, an effort

Table 1: The levels of operation

\begin{tabular}{lccccc}
\hline & $\mathrm{L}_{4-5}$ & $\mathrm{~L}_{5}-\mathbf{S}_{1}$ & $\mathrm{~L}_{3-4}$ & Both $\mathrm{L}_{4-5}$ and $\mathrm{L}_{5}-\mathbf{S}_{1}$ & Total \\
\hline Right & 19 & 8 & 2 & 2 & 31 \\
Left & 24 & 10 & 3 & 2 & 39 \\
Total & 43 & 18 & 5 & 4 & 70 \\
\hline
\end{tabular}

Table 2: The Oswestry scores of the patients (\%)

\begin{tabular}{lcc}
\hline & Mean \pm SD & Median (25-75\%) \\
\hline Before surgery & $83.1 \pm 8.2$ & $85(76-90)$ \\
$1^{\text {st }}$ month & $7.8 \pm 1.5$ & $8(7-9)$ \\
$3^{\text {rd }}$ month & $9.0 \pm 1.1$ & $9(8-10)$ \\
$6^{\text {th }}$ month & $10.8 \pm 1.5$ & $11(10-11)$ \\
$1^{\text {st }}$ year & $12.5 \pm 1.8$ & $12(11-14)$ \\
$2^{\text {nd }}$ year & $13.3 \pm 1.7$ & $13(12-15)$ \\
$3^{\text {rd }}$ year & $14.0 \pm 1.4$ & $14(13-15)$ \\
$5^{\text {th }}$ year & $15.3 \pm 1.2$ & $15(15-16)$ \\
$7^{\text {th }}$ year & $17.0 \pm 1.8$ & $17(15-19)$ \\
\hline
\end{tabular}

SD: Standard deviation 
was put forth in order to keep away from the granulation field. Following the foraminotomy, discectomy was performed. In a case whom with a sequestrated disc fragment localized above the intervertebral disc space, the former laminectomy defect was extended toward the more cranial part at which granulation ended. The dural tear was sutured primarily in all the cases it developed in.

\section{Discussion}

LDH is an important disease which seen commonly and often causes a loss of work power. Even though the blame is put on various factors in the etiology, it is known that hard working conditions and an unhealthy lifestyle are the factors to be blamed. Thus, today this is a commonly seen clinical condition which requires more operations, and we encounter more cases with recurrent disc herniation. The importance of the condition is better understood when it is considered that the most significant two factors increasing the risk of recurrence in the patients operated on are hard labor and smoking. ${ }^{[6]}$ Even though a recurrent disc herniation is radiologically observed in $25 \%$ of the asymptomatic cases in the wake of the primary surgery, the recurrent disc herniation is the major cause of the failed back surgery syndrome. ${ }^{[7,8]}$ For this reason, it's accurate management is of great importance. In the modern LDH surgery, various techniques have been identified and applied since the Love's operation was identified. ${ }^{[9]}$ Among the most commonly performed methods are open lumbar discectomy, lumbar microdiscectomy, and endoscopic discectomy take the lead together with the spinal fusion procedures. No evident result could be found in the studies conducted as to what procedures were used in the management of recurrent LDHs, yet, it was seen that there were different surgical choices varying from person to person and according to the educational background. ${ }^{[10]}$ Despite the fact that the experiences and habits of a surgeon and the surgical method he prefers are quite important, still, the most commonly used surgical technique is lumbar microsurgery. ${ }^{[1]}$

In this study, we performed the lumbar microsurgery technique as a standard in the recurrent disc herniations. When statistically analyzed, it is seen that the patients had taken advantage of such an operation, that this benefit was better felt in the first postoperative process and that although some decline was observed in time, it still was higher in comparison to the preoperative period. Technically, operated 70 patients diagnosed with recurrent $\mathrm{LDH}$ in accordance with the lumbar microsurgery principles with a lower rate of complication by creating a secure corridor through medial facetectomy until the superior facet boundary could be visible and performing laminectomy inferiorly till the location where the granulation tissue ended. The recurrent disc hernias seen in the first 6 months were excluded from the study as they were associated with performing an insufficient discectomy.

The most important point to be discussed here is whether there is the need for a posterior segmental fusion (PSF) during the surgery or not. The PSF is a technique commonly applied in recurrent disc herniations. However, considering the literature, it is seen that the lumbar microsurgery is efficient in the management of recurrent hernias. For instance, in a study where 41 patients with a recurrent hernia and radicular findings were examined, and a disc excision was compared with PSF, both of the techniques are observed to have equal efficiency. ${ }^{[11]}$ Also in this report, none of the patients presented with iatrogenic instability. In another study where 30 patients were examined, it was shown that the revision disc surgery was as efficient as the primary one in those with recurrence. ${ }^{[12]}$ Additionally, in a similar study where 27 patients who identified radicular findings were followed-up for 7 years, the lumbar discectomy in those with a disc hernia was suggested to have yielded good results. ${ }^{[13]}$

In another study where 74 articles released between 2003 and 2011 were analyzed, it was identified that the revision disc surgery in the cases with recurrent disc herniation who identified radicular findings were efficient along with the evidence level 3. In the imaging techniques where there were lumbar instability findings, on the other hand, the PSF application in the patients determined to have had lumbar degenerative changes were suggested to be important. ${ }^{[14]}$

Considering the analysis of the findings of our patients in this paper, it is seen that all of them had shown symptoms with radicular findings and that a great majority of them had been revised from a single level. The surgical technique mentioned, and the patients' benefit is at quite a good level, which is in accordance with the literature.

We observed that the ratios of LDH recurrence after epidural anesthesia (51/810-6.29\%) and general anesthesia (19/305-6.22\%) are very similar.

In the lumbar recurrent disc herniations progressing with radicular complaints and findings, the efficiency of the lumbar microsurgery to be performed by the excision of the facet medial and the enlargement of the laminectomy boundary up to the exteriority of granulation is quite 
high. The requirement for an additional fusion surgery will be understood in the prospective follow-ups.

\section{Financial support and sponsorship}

Nil.

\section{Conflicts of interest}

There are no conflicts of interest.

\section{References}

1. Dai LY, Zhou Q, Yao WF, Shen L. Recurrent lumbar disc herniation after discectomy: Outcome of repeat discectomy. Surg Neurol 2005;64:226-31.

2. Martin BI, Mirza SK, Flum DR, Wickizer TM, Heagerty PJ, Lenkoski AF, et al. Repeat surgery after lumbar decompression for herniated disc: The quality implications of hospital and surgeon variation. Spine J 2012;12:89-97.

3. Lebow RL, Adogwa O, Parker SL, Sharma A, Cheng J, McGirt MJ. Asymptomatic same-site recurrent disc herniation after lumbar discectomy: Results of a prospective longitudinal study with 2-year serial imaging. Spine (Phila Pa 1976) 2011;36:2147-51.

4. Cheng J, Wang H, Zheng W, Li C, Wang J, Zhang Z, et al. Reoperation after lumbar disc surgery in two hundred and seven patients. Int Orthop 2013;37:1511-7.

5. Shamim MS, Parekh MA, Bari ME, Enam SA, Khursheed F. Microdiscectomy for lumbosacral disc herniation and frequency of failed disc surgery. World Neurosurg 2010;74:611-6.
6. Mroz TE, Lubelski D, Williams SK, O’Rourke C, Obuchowski NA Wang JC, et al. Differences in the surgical treatment of recurrent lumbar disc herniation among spine surgeons in the United States. Spine J 2014;14:2334-43.

7. Blamoutier A. Surgical discectomy for lumbar disc herniation: Surgical techniques. Orthop Traumatol Surg Res 2013;99 1 Suppl: S187-96.

8. Kim CH, Chung CK, Jahng TA, Yang HJ, Son YJ. Surgical outcome of percutaneous endoscopic interlaminar lumbar diskectomy for recurrent disk herniation after open diskectomy. J Spinal Disord Tech 2012;25:E125-33.

9. Bokov A, Isrelov A, Skorodumov A, Aleynik A, Simonov A, Mlyavykh S. An analysis of reasons for failed back surgery syndrome and partial results after different types of surgical lumbar nerve root decompression. Pain Physician 2011;14:545-57.

10. Fu TS, Lai PL, Tsai TT, Niu CC, Chen LH, Chen WJ. Long-term results of disc excision for recurrent lumbar disc herniation with or without posterolateral fusion. Spine (Phila Pa 1976) 2005;30:2830-4.

11. Miwa S, Yokogawa A, Kobayashi T, Nishimura T, Igarashi K, Inatani $\mathrm{H}$, et al. Risk factors of recurrent lumbar disc herniation: A single center study and review of the literature. J Spinal Disord Tech 2015;28:E265-9

12. Patel MS, Braybrooke J, Newey M, Sell P. A comparative study of the outcomes of primary and revision lumbar discectomy surgery. Bone Join J 2013;95-B: 90-4.

13. Aizawa T, Ozawa $\mathrm{H}$, Kusakabe $\mathrm{T}$, Nakamura $\mathrm{T}$, Sekiguchi A, Takahashi A, et al. Reoperation for recurrent lumbar disc herniation: A study over a 20-year period in a Japanese population. J Orthop Sci 2012;17:107-13.

14. Wang JC, Dailey AT, Mummaneni PV, Ghogawala Z, Resnick DK, Watters WC $3^{\text {rd }}$, et al. Guideline update for the performance of fusion procedures for degenerative disease of the lumbar spine. Part 8: Lumbar fusion for disc herniation and radiculopathy. J Neurosurg Spine 2014;21:48-53. 